\title{
O USO DE SUBSTÂNCIAS PSICOATIVAS NO AMBIENTE DE TRABALHO
}

\section{ARTIGO DE REVISÃO}

SENARELLI, Renata Maria ${ }^{1}$

SCATOLIN, Henrique Guilherme ${ }^{2}$

SENARELLI, Renata Maria SCATOLIN, Henrique Guilherme. 0 uso de substâncias psicoativas no ambiente de trabalho. Revista Científica Multidisciplinar Núcleo do Conhecimento. Ano 05, Ed. 03, Vol. 08, pp. 131-140. Março de 2020. ISSN: 24480959, Link de

acesso: https://www.nucleodoconhecimento.com.br/psicologia/substanciaspsicoativas

\section{RESUMO}

$\mathrm{Na}$ última década, muito se tem avaliado sobre os riscos psicossociais nos quais o adoecimento mental e outros problemas como o consumo de substâncias psicoativas lícitas e ilícitas estão vinculados ao contexto do trabalho. O presente estudo teve como objetivo realizar um levantamento sobre a forma como esses comportamentos são vistos e abordados dentro das organizações. Concluiu-se que programas de prevenção existentes nas organizações são de extrema importância e diante disso é de extrema necessidade maiores investimentos na área de prevenção, de forma que a organização, como um todo, em especial os líderes, se conscientizem e sejam orientados a lidar com tal fenômeno.

\footnotetext{
${ }^{1}$ Especialista em Psicologia Organizacional e do Trabalho, graduada em Psicologia pela Fundação Hermínio Ometto.

2 Doutor em Psicologia.
} 
Palavras-chave: Trabalho, dependência química, sofrimento, programas de prevenção.

\section{INTRODUÇÃO}

Nas últimas décadas, muito se tem avaliado sobre os riscos psicossociais no contexto laboral e dentre esses aspectos podemos citar o uso de substâncias psicoativas como fenômenos que nos fazem refletir e questionar o modo de atuar e de desempenhar as funções do trabalhador nas organizações, ou seja, um olhar sobre a saúde (ou falta dela) como reflexo dentro deste contexto.

Ao pensarmos em riscos psicossociais, podemos refletir concomitante a isso, que as condições de trabalho atualmente estão associadas a novas tecnologias e funcionamento das produções dentro das empresas. Com isso, podemos nos questionar como o trabalho afeta o indivíduo, como também em sua vida social, acarretando supostamente o uso abusivo de substâncias psicoativas como formas de enfrentamento para alívio e possível bem-estar emocional.

São inúmeras as situações que levam o indivíduo, dentro do trabalho, a fazer uso de alguma substância que afete a sua percepção, humor, comportamento e consciência. De acordo com Roberto, Conte, Rocha, Torossian e Vianna (2002) nem todos os indivíduos estabelecem a mesma relação com a droga, voltando a atenção para os determinantes sociais e institucionais, cada um a seu modo com prejuízos subjetivos, orgânicos, profissionais e sociais.

Os autores Corrêa, Pedrozo e Cazenave (1998) destacam que, na atualidade, consumir drogas e álcool tem apresentado uma grande relação com os locais de trabalho, como também destacam que é um fato a maioria dos usuários serem trabalhadores.

Diante disso é de extrema importância voltarmos o olhar para a relação existente entre o homem e trabalho, nos questionando e identificando a forma de conduta das empresas perante a saúde, bem-estar físico e mental dos indivíduos, como também a 
sua vida no âmbito social. Podemos pensar que são inúmeras as situações dentro das empresas que podem levar o trabalhador a fazer uso abusivo de álcool e outras drogas, culminando assim, no adoecimento deste sujeito.

A partir das colocações citadas acima, esse trabalho visa discorrer sobre a problemática do uso/abuso de álcool e substâncias psicoativas dentro das empresas, sendo este um fator de adoecimento, afastamentos e rotatividade, como também a manutenção de programas de prevenção existentes, que buscam como forma de trabalho abordar tais fenômenos.

\section{METODOLOGIA}

Esta pesquisa tem por objetivo refletir sobre o uso abusivo de álcool e drogas nas empresas e organizações, trazendo a luz a problemática do trabalho como algo que pode adoecer e disparar tal consumo como uma forma de reação a fenômenos existentes na cultura e modo de funcionamento de tal organização. Para tal, neste trabalho foi realizado um levantamento dos programas já realizados de prevenção ao uso de álcool e os programas de qualidade de vida, com o intuito de compreender como esse fator de adoecimento vem sendo trabalhado nas empresas, ou seja, como os líderes compreendem a importância do trabalho de prevenção como uma forma de acolhimento ao trabalhador, sendo esta uma questão de saúde que tanto o afeta, e como consequência, a empresa e seu desenvolvimento. Assim, o método de pesquisa utilizado foi embasado em um levantamento bibliográfico, a partir de uma revisão da literatura já existente, uma vez que a mesma permitiu citar e abordar as formas de entendimento de tais questões.

\section{FUNDAMENTAÇÃO TEÓRICA}

Grandes transformações na produção industrial ocorreram a partir da implementação de novas tecnologias, gerando uma modernização nas condições de trabalho e mudanças no plano social e individual, afetando a atividade ocupacional e o bem-estar emocional do trabalhador (GUIMARÃES et. al. 1999). 
Portanto, pensar o trabalho é pensar na constituição do indivíduo em sua singularidade, como um marco social em sua vida a qual o torna membro da sociedade, de forma produtiva, ou mesmo incapacitante, com ou sem saúde mental, sendo essa percepção um tanto antiga, como esboçado até mesmo no filme Tempos Modernos, de Charlie Chaplin.

Sobre o adoecimento do trabalhador, Dejours (1992) reflete sobre esta questão e se propõe a responder sobre de que forma e como fazem para resistir aos ataques do funcionamento ao psiquismo provocado pelo trabalho, porém, o objeto de estudo, para este autor, não passa a ser a loucura e sim todo o sofrimento que o mesmo implica e seus mecanismos de regulação no trabalho.

Mais do que um estudo voltado para identificar doenças mentais específicas correlacionadas a profissão ou situações de trabalho, a abordagem da nova psicopatologia do trabalho está preocupada com a dinâmica mais abrangente, que se refere à gênese e às transformações do sofrimento mental vinculadas à organização do trabalho. Não obstante, problemas especiais, como a fadiga, tem sido objeto de atenção, assim como a questão do uso de bebidas alcoólicas em sua relação a certas vivências do trabalho, nas quais esse uso se configura estratégia defensiva muitas vezes de caráter coletivo (DEJOURS, ABDOUCHELI e JAYET, 1994, p. 14-15).

Em relação ao uso abusivo de álcool e outras substâncias psicoativas nas organizações, Roberto, Rocha e Torossian ( 2002) destacam que há algum tempo, as consequências ligadas a esses fenômenos eram subestimadas ou negadas, minimizando tais efeitos. Já na atualidade destacam que as empresas privadas e públicas se preocupam com o aumento e incidência dessas situações.

De acordo com Rossato e Kirchhof (2004) o problema do alcoolismo no campo do trabalho pode ser considerado como um problema social a ser melhor compreendido por todas as pessoas que interagem no contexto da saúde e de uma instituição pública. Identificar o alcoolismo no campo da organização necessita de um contato 
mais apurado dentro de tal ambiente, compreendendo assim toda a complexidade que envolve carga horária, atribuições, responsabilidades e a qualidade da produção.

Os autores citados acima apontam que algumas iniciativas de programas de prevenção, dentro das empresas, começaram em meados da década de 80 , mesmo diante de pouco interesse por um número pequeno de técnicos e contando com algumas atividades isoladas.

Por exemplo, Rossato e Kirchhof (2004) voltaram-se para a investigação que teve o alcoolismo no trabalho, abordando como uma área de intervenção a ser melhor compreendida por todos aqueles que interagem no contexto da saúde de uma instituição pública. Apontaram que a avaliação de um programa de tratamento para o alcoolismo com funcionários de uma universidade pública mostrou o alcoolismo como motivo de absenteísmo, como o motivo de aposentadorias precoces e de acidentes de trabalho.

Em relação aos programas implantados perante as perdas, dentre elas da qualidade e produtividade para o empregador, Martins (2004) destaca que os supervisores são considerados primordiais para o desenvolvimento de um programa de prevenção bem sucedido, ou seja, é de extrema importância que os mesmo estejam preparados para o novo papel e para as responsabilidades atribuídas a tal programa como este.

Sobre programas para controle de álcool e drogas, Corrêa (1998) cita dois tipos deles que visam identificar o usuário, incentivando o mesmo a receber tratamento e assistência, porém os problemas como o abandono do local de trabalho e a invasão da privacidade podem ser utilizados de forma incorreta para intimidar os trabalhadores. Os programas que podem ser adotados são os testes pré admissional, sendo os mais comuns e amplamente aceitos e a análise toxicológica, dentre eles os testes de triagem e confirmação.

Segundo o SENAD são inúmeros os benefícios citados a favor do programa de prevenção do uso de álcool e outras drogas. Dentre eles, podemos citar palestras como prevenção primária, redução de absenteísmo, assistência médica, atrasos e 
licenças, aumento da produção e lucratividade, possibilidade da criação de novos empregos, redução do custo dos negócios e menor frequência dos problemas disciplinares (FERREIRA e SARTES, 2015, p.98).

Lacerda (1999) enfatizou que o tratamento relacionado ao álcool e drogas, no que tange ao tratamento psicológico e psiquiátrico, corresponde a apenas um valor pequeno do custo total, porém com grande investimento para os empregadores e para órgãos governamentais.

Sobre os programas de prevenção e intervenção, Roberto et. al. (2002) trazem para reflexão a concepção que chamam de sintoma social e como forma de proposta terapêutica, partem do ponto da singularidade para o enfrentamento de situações, não apenas visando o aumento de produtividade.

Rodríguez-Martos (1998 citado por MARTINS, 2004) destaca que os primeiros programas de prevenção ao alcoolismo no ambiente de trabalho surgiram nos anos 40 nos EUA, apoiados no grupo de apoio AA (Alcóolicos Anônimos), servindo como base de apoio as PAEs (Programas de Assistência ao Empregado). Seguindo com esse modelo, os trabalhadores alcoolistas eram encaminhados ao AA, sendo esse modelo de intervenção ampliado para qualquer necessidade além da questão do álcool como também em sua vida pessoal ou familiar.

Segundo o autor, esses programas inicialmente seguiam o modelo conceitual de doença, que ainda é o mais frequente, sendo 'implantados nas empresas pelo serviço social e/ou médico, com treinamento de chefias para identificação do empregado com problemas, confronto e encaminhamento para tratamento em clínicas especializadas', utilizando também o modelo do AA (MARTINS, 2004, p. 221).

E, por fim, Déa, Santos, Itakura e Olic (2004) discorrem sobre um programa de prevenção que leva em consideração aspectos motivacionais, de desenvolvimento e elementos de informação, sendo um programa de redução de danos, ou seja, seu 
principal objetivo não é a abstinência ou a diminuição do uso de bebidas alcóolicas e sim reduzir comportamentos de risco dos danos produzidos pelo consumo de álcool.

\section{RESULTADOS}

Como já discutido anteriormente na fundamentação teórica, o uso abusivo de álcool e substâncias psicoativas dentre de organizações e empresas é um fenômeno que necessita de uma visão mais abrangente e investigativa, como também de acolhimento, para assim amparar o trabalhador e prevenir a empresa de problemas que interfiram diretamente em seu desenvolvimento gerando situações como absenteísmo e baixa produtividade.

De acordo com Lacerda (1999), as empresas, nas últimas décadas, tem mostrado uma mudança significativa na maneira de valorizar cada vez mais a presença dos departamentos de recursos humanos, avaliando frequentemente a satisfação profissional dos funcionários, deixando de lado o controle rígido e coercitivo para com os mesmos, transformando a relação com o colaborador em uma relação de parceria. As maneiras de lidar com o abuso de álcool seguem mudando de uma perspectiva de educação para promoção de saúde, acentuando a importância do capital humano dentro das empresas.

Ao pensarmos em políticas do álcool, Laranjeira e Duailibi (2007) destacam que:

São consideradas políticas do álcool aquelas que dizem respeito à relação entre álcool, segurança, saúde e bem-estar social. Definem-se políticas do álcool como qualquer esforço ou decisão de autoridades governamentais ou de organizações não governamentais (ONG) para minimizar ou prevenir problemas relacionados ao álcool (p.841).

Ao considerarmos os conceitos trabalhados até então, essa discussão tem como paralelo o aporte teórico da psicodinâmica do trabalho, teoria essa que traz como proposta a investigação e reflexão do trabalho diretamente associado ao adoecimento ou não dentro do contexto organizacional. 
Sobre a psicodinâmica do trabalho, compreende-se como a escola que se edificou baseada nas ideias de Christophe Dejours, ao qual aponta que as situações de trabalho conduziriam, algum momento, ao prazer, já em outro, ao sofrimento e ao modo como poderiam seguir diferentes desdobramentos, culminando em patologias mentais ou psicossomáticas, ampliando o olhar além da dinâmica da saúde-doença (SILVA, 1994).

Complementando Silva (1994), Merlo (2007) destaca:

A utilização do conceito de Psicodinâmica do Trabalho, em substituição ao de Psicopatologia do Trabalho, deu-se a partir de um privilegiamento do estudo da normalidade, sobre o da patologia. O que importa para a Psicodinâmica do Trabalho é conseguir compreender como os trabalhadores alcançam manter um certo equilíbrio psíquico, mesmo estando submetidos a condição de trabalho desestruturantes (DEJOURS Apud MERLO, 1993).

Seguindo com Dejours (1992) em seu livro A Loucura do Trabalho, o autor fala da função da ideologia defensiva ao qual vai além de um sistema defensivo. Seguindo, embasado nesse raciocínio, cita o alcoolismo que atinge certo número de indivíduos, sendo para ele uma saída individual, condenada pelo grupo social, correspondendo a uma fuga em direção a uma decadência mais rápida. Cita também outras saídas como atos de violência e, por fim, a loucura como forma de descompensação psicóticas e depressivas. "Enfim, sem poder usar estas diferentes "portas de saída", o risco é a morte" (p.34-35).

Porém, a Psicodinâmica do Trabalho não se limita a apenas olhar o sofrimento do trabalhador e sim suas origens e também destaca a relação de prazer que pode existir entre o homem e o desempenho de suas funções laborais. É importante a compreensão da maneira como se mostram os dois lados do trabalho, sendo importante para tentar interpretar de forma mais ampla a relação saúde e trabalho, como também procurando, portanto, alternativas de satisfação. (JACQUES e CODO, 2007, p. 139). 
Neste contexto, ao voltarmos a atenção para o alcoolismo, os autores Rossato e Kirchhof (2004) destacam-o como uma patologia que, após um tempo de conflitos e recaídas, pode afetar o alcoolista em sua vida produtiva, sendo diretamente as implicações nas relações de trabalho.

\section{CONCLUSÃO}

Este trabalho de pesquisa teve como objetivo refletir e discutir a relação existente entre o trabalho e o uso abusivo de álcool e drogas nos respectivos ambientes organizacionais e como as empresas se mobilizam perante tais fenômenos comportamentais, sendo realizado um levantamento de alguns programas de prevenção existentes e as formas de enfrentamento utilizados pelas mesmas.

As formas de enfrentamento encontradas pelas empresas variam entre programas de prevenção e testes realizados durante o processo admissional. Foi observado que os artigos e livros estudados seguem realizando o levantamento de todo ambiente organizacional, ou seja, não excluem ou voltam o problema do uso de álcool e drogas somente para o trabalhador e sim realizaram uma investigação de forma ampla, abrangendo o meio a qual está inserido, considerando a cultura organizacional, ambiente familiar e o social.

Sendo assim, para complementar, agregando a todo conhecimento levantado e adquirido, a Psicodinâmica do trabalho tem como outra característica importante a coletividade do trabalho, ou seja, olhar para o indivíduo não de forma isolada e, após identificar o sofrimento psíquico do indivíduo nas situações de trabalho, buscar intervenções voltadas para a organização do trabalho ao qual o indivíduo está inserido (JACQUES e CODO, 2007).

Para finalizar, após todo conteúdo levantado durante essa pesquisa, é de extrema importância que esse tema possa continuar sendo estudado e que novas propostas de prevenção possam ser desenvolvidas, dando o necessário suporte tanto ao trabalhador de forma individual, como também ao contexto organizacional, conscientizando cada vez mais os líderes de modo que o ambiente de trabalho seja 
um dos menores fatores contribuintes e desencadear para o uso abusivo de drogas lícitas e ilícitas.

\section{REFERÊNCIAS}

CORRÊA, C. L.; PEDROZO, R. C.; CAZENAVE, S.O.S. Aspectos relacionados aos programas de controle e prevenção do uso de álcool e drogas no local de trabalho. Revista Ciências Médicas, Campinas, v.7, n3, p. 85-90, set/dez. 1998.

DÉA, H. R. F. D.; SANTOS, E. N. S.; ITAKURA, E. OLIC, T. B. A inserção do psicólogo no trabalho de prevenção ao abuso de álcool e outras drogas. Revista Psicologia: Ciência e Profissão, v.24, n. 1, p. 108-115, 2004.

DEJOURS, C. A loucura do trabalho: estudo de psicopatologia do trabalho. São Paulo: Cortez, 1992.

DEJOURS, C.; ABDOUCHELI, E.; JAYET, C. Psicodinâmica do trabalho: contribuições da Escola Dejouriana à análise da relação prazer, sofrimento e trabalho. São Paulo: Atlas, 1994.

DUAILIBI, S.; LARANJEIRA, R. Políticas públicas relacionadas às bebidas alcoólicas. São Paulo: Rev. Saúde Pública, 2007. Acessado em: 26/08/2018.

FERREIRA, M. L.; SARTES, L. M. A.; Intervenções Realizadas no Ambiente de Trabalho para o Uso de Drogas: Revisão Sistemática. Revista Psicologia: Ciência e Profissão/Conselho Federal de Psicologia, Brasília, v.1, n1, p. 96-109, 2015.

JACQUES, M. G.; CODO, W. Saúde Mental e Trabalho: leituras. Petrópolis: Vozes, 2007.

LACERDA, A. L. T., Àlcool e Local de Trabalho. In: GUIMARAES, L. A. M.; GRUBITS, S. Série Saúde Mental e Trabalho. São Paulo: Casa do Psicólogo, 1999. 
MARTINS, D. A., Programas de prevenção ao alcoolismo no trabalho. In: GUIMARAES, L. A. M.; GRUBITS, S. Série Saúde Mental e Trabalho. São Paulo: Casa do Psicólogo, 2004.

ROBERTO, C. S.; CONTE, M.; MAYER, R. T. R.; DJAMBOLAKDJIAN, T.; VIANNA, T. R. Drogas e Trabalho: uma Proposta de Intervenção nas Organizações. Revista Psicologia: Ciência e Profissão, v.22, n 1, p.18-29, 2002.

ROSSATO, V. M. D.; KIRCHHOF, A. L. C. O trabalho e o alcoolismo: estudo com trabalhadores. Brasília: Rev. Bras. Enfermagem, 2004. Disponível em: http://www.scielo.br/pdf/reben/v57n3/a18v57n3.pdf. Acessado em: 27/08/2018.

SILVA, E. S. Trabalho e desgaste mental: o direito de ser dono de si mesmo. São Paulo: Cortez editora, 2011.

Enviado: Setembro, 2019.

Aprovado: Março, 2020. 